\title{
Hasil Belajar Siswa Saat Pandemi Covid-19 Melalui Home Visit Studi di MI Salafiyah Kranggan
}

\section{Student Learning Outcomes During the Covid-19 Pandemic Through Home Visit Study at MI Salafiyah Kranggan}

\author{
Hamidullah Ibda ${ }^{1}$ Dwi Nur Laeli ${ }^{2}$ \\ ${ }^{1,2}$ Sekolah Tinggi Agama Islam Nahdlatul Ulama' Temanggung \\ e-mail: 'h.ibdaganteng@stainutmg.ac.id, 2dwinurlaeli44@gmail.com
}

\begin{abstract}
Abstrak: Penelitian ini membahas mengenai hasil belajar siswa saat pandemi covid-19 melalui kegiatan home visit studi di MI Salafiyah Kranggan. Tujuan dari penelitian ini yaitu menganalisis hasil belajar siswa saat pandemi melalui kegiatan home visit studi di MI Salafiyah Kranggan. Penelitian menggunakan metode kualitatif eksploratif. Objek dari penelitian ini yaitu home visit serta hasil belajar siswa dan subjek dari penelitian ini guru kelas 2 B dan siswa kelas 2 B di MI Salafiyah Kranggan. Hasil dari penelitian ini, dengan adanya home visit 21 siswa kelas 2 B MI Salafiyah Kranggan memperoleh hasil belajar yang baik, selain itu dapat mengurangi sedikit kesulitan yang dialami guru, peserta didik dan orang tua. Berdasarkan penelitian yang telah dilaksanakan, kesimpulan dari penelitian ini yaitu: 1) Kebijakan pembelajaran daring dapat menunjang hasil belajar siswa, yaitu melalui home visit. Hal ini terbukti dari hasil penelitian yang dihimpun di lapangan dari 21 peserta didik kelas 2 B MI Salafiyah Kranggan menyatakan hasilnya baik. Tanggapan peserta didik mengenai pembelajaran daring, menginginkan kegiatan pembelajaran dilaksanakan seperti dulu lagi. 2) Home visit dilaksanakan dua minggu sekali dengan tujuan mengevaluasi pembelajaran daring yang sudah terlaksana.
\end{abstract}

Kata Kunci: hasil belajar, home visit, pandemi.

Abstract: This study discusses the students' learning outcomes during the covid-19 pandemic through home visit activities at MI Salafiyah Kranggan. This study aims to analyze the students' learning outcomes during the covid-19 pandemic through home visit activities.The research used a qualitative exploratory method. The subjects of this study are 2 nd Grade students for Class $B$ and their teacher. As a result, through the home visit study, the 21 students of 2 nd-grade class B MI Salafiyah Kranggan obtained good learning results. In addition, the home visit program is good to help the teachers and the parents in applying the learning during the covid-19 pandemic. Therefore, a home visit can support the learning outcomes. The conclusions of this study are: 1) The home visit can bolster the learning outcomes during online learning. It showed in the learning outcomes of 21 students. The students also responded to the online learning policy that they want the learning activities could be operating used to be. Thus, the home visit has been conducted once in two weeks to evaluating the learning activities continuously.

Keywords: learning outcomes, home visit, pandemic. 

License. Allows readers to read, download, copy, distribute, print, search, or link to the full texts of its articles and allow readers to use them for any other lawful purpose.

Copyright (c) 2021 Hamidullah Ibda dan Dwi Nur Laeli

Received 05 Januari 2021, Accepted 07 Februari 2021, Published 11 Mei 2021

\section{A. Pendahuluan}

COVID-19 merupakan penyakit yang menular, yang disebabkan oleh sindrom pernapasan akut coronavirus 2 (acute respiratory syndrome coronavirus 2). Ketika menyerang manusia, coronavirus biasanya menyebabkan penyakit infeksi saluran pernapasan, seperti flu, MERS (Middle-East respiratory syndrome), dan SARS (severe acute respiratory syndrome) (Dwi \& dkk, 2020). Tahun 2020 menjadikan tahun yang sangat berat bagi semua orang, hingga sampai saat ini Indonesia dilanda pandemic COVID-19.

Terkait mengenai situasi pandemi, siswa pun tidak sekadar diliburkan melainkan tetap melaksanakan proses pembelajaran dari rumah. Siswa dapat melaksanakan proses pembelajaran secara daring dengan memanfaatkan internet dan gadget agar di masa pandemi ini semangat belajar siswa tidak tumbang, karena pendidikan merupakan prioritas utama. Oleh karena itu agar tidak berhenti dalam proses pembelajaran di tengah-tengah wabah ini peserta didik melakukan pembelajaran online (Risalah \& dkk, 2020). Selain itu guru juga dapat mengadakan kegiatan home visit.

Guru kelas di setiap sekolah mempunyai tanggung jawab mendidik pada salah satu kelas untuk mentransfer ilmu dari materi semua mata pelajaran, kecuali pelajaran PJOK atau olahraga dan Pendidikan Agama. Dikarenakan mengajar seluruh mata pelajaran, pada praktiknya guru hanya memburu target penuntasan kurikulum supaya terlaksana dengan baik dan menjadikan suatu hal yang teknis dalam praktik Pendidikan terbengkalai (Dwita \& dkk, 2018).

Tanggung jawab guru yang berperan sebagai pendidik hendaklah mampu bekerja sama dengan berbagai pihak, terkhusus dapat menjadikan perantara di antara orang tua dan pihak sekolah untuk menerapkan metode pembelajaran di masa pandemi yang tengah berlangsung hingga saat ini (Suhendro, 2020). Dengan begitu Home visit menjadi salah satu strategi untuk pembelajaran di masa pandemi ini, menjadi alternatif untuk mentransfer pengetahuan kepada peserta didik.

Home visit menjadi salah satu tindakan dalam menerima data keterangan, berupa komitmen untuk menuntaskan berbagai kondisi siswa yang meliputi keadaan siswa di rumah, sarana dan prasarana, jalinan siswa dengan anggota keluarga, kepribadian siswa dan peranan orang tua dalam memerhatikan perkembangan siswa (Amalia, 2016). Dengan adanya bimbingan yang diberikan guru saat home visit menjadikan peserta didik lebih termotivasi menyelesaikan tugasnya dan mengerjakan dengan baik. 
Guru dapat mengambil peluang adanya home visit yaitu untuk mengetahui kemajuan setiap siswa selama belajar daring. Usaha ini dilaksanakan oleh guru untuk mewujudkan pembelajaran yang maksimal bagi peserta didik (Amalia, 2016). Adanya interaksi dan timbal balik yang cukup dapat membantu guru untuk menghindari kesalahan dalam proses pengembangan potensi peserta didik di rumah.

Proses pembelajaran daring menunjukkan dampak positif dan signifikan terkait adanya implementasi strategi home visit yang telah terselenggara (Nirmala \& Haerul, 2021). Adanya home visit dapat memperuntukkan dampak yang menguntungkan baik langsung maupun tidak langsung, yang pada hakikatnya akan merujuk pada terwujudnya suatu pendidikan (Dwita \& dkk, 2018). Eksistensi home visit dapat menunjang dunia pendidikan yang berperan mencari jalan keluar setiap kendala yang dihadapi peserta didik dalam pembelajaran.

Menteri Pendidikan memberikan kebijakan mengenai pengelolaan proses pembelajaran, yang menghimbau untuk dilaksanakan di rumah masing-masing peserta didik dengan memanfaatkan sistem dalam jaringan (daring) (Nirmala \& Haerul, 2021). Home visit menjadi sangat urgent tentunya di masa pandemi saat ini, karena dengan kegiatan tersebut guru dapat melihat perkembangan anak supaya mendapat hasil belajar yang baik.

Bagi Sekolah yang masih dalam keadaan tidak bisa melaksanakan KBM (kegiatan belajar mengajar), guru bisa mengaplikasikan kretivitasnya agar dimanfaatkan sebagai media alternatif dalam belajar selama daring. Guru bisa memanfaatkan sumber belajar yang telah disediakan seperti buku siswa, sesuai dengan tema-tema dan disesuaikan dengan jadwal yang telah dibuat sebelumnya agar lebih terstruktur (Aji \& Dewi, 2020).

Salah satu program yang diagendakan di MI Salafiyah Kranggan saat pandemi yaitu home visit, untuk menjalin interaksi yang dinamis dan sinergis di antara pihak sekolah, orang tua siswa, dan masyarakat (N. P. Sari \& Juniarti, 2019). Hal itu disebabkan karena pendidikan suatu peranan penting antara sekolah, keluarga dan masyarakat. Oleh karennya diperlukan dukungan dari semua pihak agar terciptanya komitmen orang tua dengan guru dalam rangka memperoleh hasil belajar yang maksimal.

Mengikuti arahan dari pemerintah, MI Salafiyah Kranggan mewajibkan seluruh siswanya untuk belajar dari rumah. Dalam pelaksanaannya, para siswa tetap mendapatkan pembelajaran, tugas dari guru dan program home visit. Penelitian ini berupaya untuk menggali apakah home visit berdampak pada hasil belajar siswa di MI Salafiyah Kranggan dari adanya pandemi ini.

\section{B. Metode}


Penelitian menggunakan metode kualitatif eksploratif untuk mengetahui informasi mengenai hasil belajar siswa saat pandemi melalui home visit studi di MI Salafiyah Kranggan. Penelitian ini dilakukan bulan Desember 2020, sedangkan objek dari penelitian ini yaitu pelaksanaan home visit studi serta hasil belajar siswa. Adapun penelitian ini yaitu guru kelas 2 B dan siswa kelas 2 B di MI Salafiyah Kranggan. Metode pengumpulan data primer dilakukan melalui wawancara Kepala Sekolah dan Wali Kelas 2 B, observasi, dan dokumentasi, sedangkan data sekunder dikumpulkan dari data yang dipublikasikan seperti jurnal-jurnal online.

\section{Hasil dan Pembahasan}

Transformasi pendidikan lantaran adanya COVID-19 sangat kentara, berawal dari proses pembelajaran yang dilaksanakan dengan cara daring. Tentunya tidak segenap tenaga pendidikan piawai mengikuti arus teknologi yang begitu pesat dan mengaplikasikannya dalam pembelajaran daring (online). Begitu sulitnya keadaan ini tetapi yakinlah bahwa proses pembelajaran dapat dilaksanakan dimanapun dan kapanpun ketika ada kemauan.

Kebijakan pembelajaran daring dapat menunjang hasil belajar, yaitu melalui kegiatan home visit. Hal ini kentara dari hasil yang terhimpun di lapangan dari 21 siswa kelas 2 B MI Salafiyah Kranggan menyatakan hasilnya baik, dikarenakan siswa dapat lebih leluasa mencari jawaban dari tugas yang diberikan oleh guru. Selain itu siswa juga didampingi orang tua saat mengerjakan tugas, hal itu membuat hasil belajar menjadi lebih maksimal.

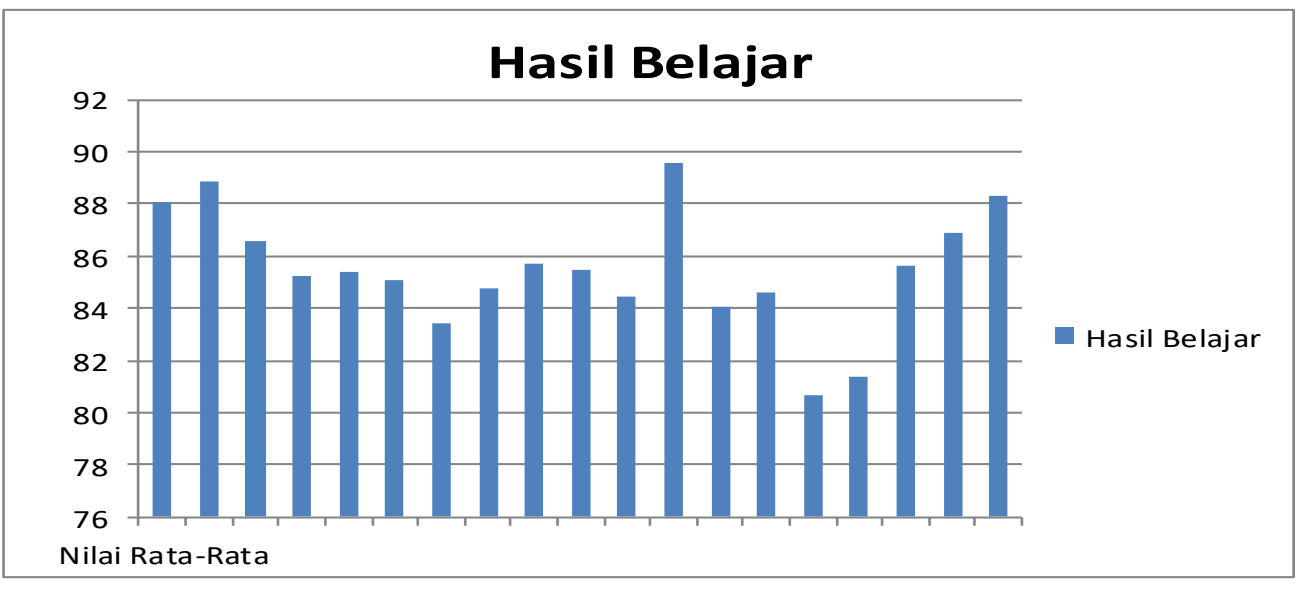

Gambar 1. Hasil Belajar Kelas 2 B MI Salafiyah Kranggan

Tabel 1. Skala Penilaian Hasil Belajar 


\begin{tabular}{|c|c|c|c|}
\hline No. & Nilai & Predikat & Keterangan \\
\hline 1. & $86-100$ & A & Sangat baik \\
\hline 2. & $71-85$ & B & Baik \\
\hline 3. & $61-70$ & C & Cukup \\
\hline 4. & $50-60$ & D & Kurang \\
\hline
\end{tabular}

Sekolah mempunyai peranan yang berpengaruh dalam upaya menunjang siswa supaya terlaksana dengan maksimal kegiatan pembelajaran daring (online). Tujuan dilakukan kegiatan home visit tersebut guna memahami kondisi anak dan dalam melakukan proses pengajaran yang sesuai dengan kondisi anak (Ziah \& Erny, 2013). Hal itu untuk meningkatkan peforma hasil belajar siswa.

Pada dasarnya siswa memiliki potensi yang tidak terbatas (Zahra, Wardhani, \& Krisnani, 2020). Tanggapan siswa mengenai pembelajaran daring, tidak sedikit dari mereka berkeberatan karena jenuh dengan pembelajaran secara daring melalui grup WhatsApp yang dilakukan setiap minggu. Siswa mengharapkan proses pembelajaran dilaksanakan seperti sediakala karena dapat melihat langsung sosok gurunya, mendengarkan paparan yang disampaikan, bernyanyi bersama, dan dapat bertanya secara langsung jika terdapat materi yang belum dipahami.

Selanjutnya orang tua pun merasa bingung karena dituntut berperan menjadi seorang guru untuk anaknya di rumah. Orang tua pada akhirnya harus ikut memahami materi agar bisa mengajari dan membantu dalam proses penugasan. Ketika siswa dituntut untuk melakukan pembelajaran melalui berbagai cara dapat berupa audio atau video, mereka perlu mengikut-sertakan orang tua, di samping itu peran orang tua juga melakukan aktifitas untuk memenuhi kebutuhan ekonomi dan rumah tangga sehingga tugas menjadi terkendala.

Banyak orang tua yang memotivasi siswa supaya mendapat hasil optimal, hal ini membuat tidak sedikit dari orang tua yang sengaja untuk meluangkan waktunya demi membantu proses pembelajaran anaknya selama di rumah. Walaupun tidak sedikit juga merasa hal itu menjadi tambahan aktivitas orang tua selain mengerjakan tugas rumah tangga, terlebih bagi orang tua yang bekerja. The real teacher di masa pandemi adalah orang tua. 


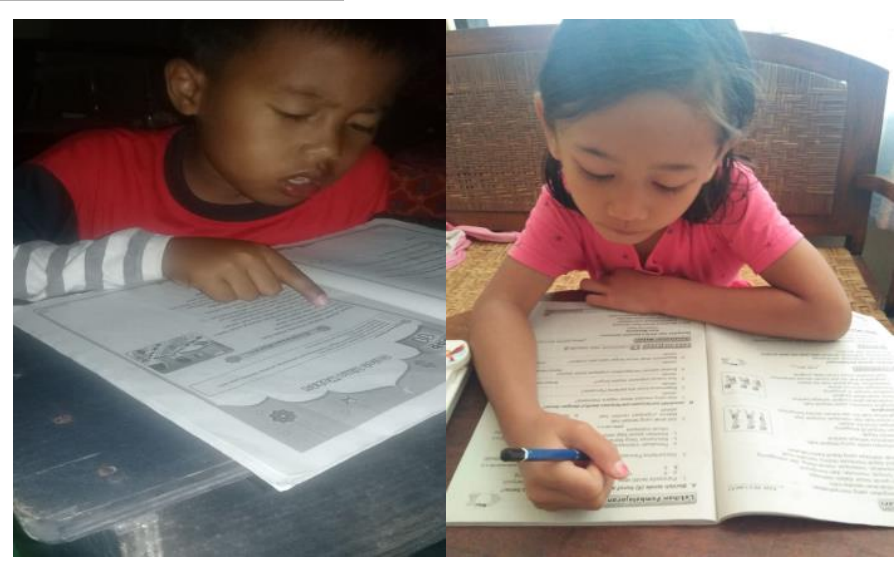

Gambar 1. Siswa Kelas 2 B MI Salafiyah Kranggan saat Mengerjakan Tugas di Rumah

Sejak adanya pandemi, siswa setiap hari diharuskan untuk mengerjakan tugas yang diberikan lewat grup WhatsApp. Dikarenakan banyaknya materi yang belum dikuasai sementara tugas yang diberikan terus menumpuk. Untuk mengatasi hal tersebut MI Salafiyyah Kranggan mengadakan home visit agar siswa tidak mengalami kesulitan untuk memahami materi dan saat mengerjakan tugas, sehingga dapat memperoleh hasil belajar yang baik.

Tak jarang dijumpai orang tua yang begitu kewalahan dan stres menghadapi peserta didik dalam aktifitas pembelajaran di rumah. Dengan anggota keluarga tentunya menjadi salah satunya ujung tombak terwujudnya proses pembelajaran daring (Tanjung Sari, 2020). Siswa pun akan menyadari pada dasarnya tidak hanya dirinya yang mempunyai keinginan untuk sukses melainkan orang tua pun berkeinginan serupa.

Oleh karena itu dengan adanya home visit dapat mengurangi sedikit kesulitan yang dialami orang tua dalam pembelajaran daring. Kendala yang dihadapai adalah kesulitan mengkondisikan anak, keterbatasan waktu, kesulitan memahami dan memberikan pemahaman materi, dan kendala faktor lingkungan serta sumber daya yang dimilikinya (Sabiq, 2020).

Kepala Sekolah MI Salafiyah Kranggan juga mengatakan tugas orang tua sekedar untuk mendampingi siswa belajar bukan mengajari, ketika waktunya belajar siswa didampingi untuk belajar. Orang tua bisa mengajari melalui buku tema sebagai media pembelajaran, atau bisa melalui Youtube dan buku yang sudah diberikan oleh pihak sekolah.

Wali Kelas 2 B MI Salafiyah Kranggan mengatakan mengalami berbagai kendala dikarenakan pernyataan pembelajaran daring yang diinstruksikan pemerintah yang tidak terduga. Guru tampaknya mendadak untuk memaksimalkan proses pembelajaran daring. Tidak hanya itu, masalah lainnya terdapat guru yang belum mahir mengaplikasikan berbagai metode pembelajaran dan penggunaan media sosial dalam pelaksanaan pembelajaran daring (online). 
Walaupun di rumah pembelajaran dilakukan bersama orang tua, akan tetapi peran guru sebagai pendidik tetap harus bertanggung jawab, apalagi tidak semua anak dan orang tua dapat mengikuti perkembangan media sosial. Tidak cukup itu saja, terdapat permasalahan lainnya seperti signal dan gadget. Kondisi signal tiap tempat berbedabeda, adakalanya di tempat tertentu signal tidak mendukung prlaksanaan pembelajaran jarak jauh. Selanjutnya dari gadget, sebagai syarat untuk mengikuti pembelajaran daring, orang tua dituntut harus memegang gadget. Bagi yang tidak mempunyai gawai mau tidak mau harus mengambil tugas ke sekolah dengan protokol kesehatan tentunya, demi mengikuti proses pembelajaran daring dari rumah.

Pendidikan karakter dalam pembelajaran di masa pandemi memiliki peran dalam mengembangkan karakter siswa yang baik dan dapat diimplementasikan dalam kehidupan sosial (Setiawan, 2021). Pendidikan karakter menjadi sangat penting di masa pandemi ini untuk memantau siswa selama di rumah sebagai pembentuk nilai spiritual terhadap kepribadiannya, agar tidak kacau dan tersentuh oleh nilai-nilai Islam dalam jiwanya. Penanaman moral bagi siswa tidak hanya kewajiban seorang guru, melainkan termasuk seluruh pihak termasuk orang tua.

Akibat ditiadakannya proses pembelajaran tatap muka dalam upaya mencegah penyebaran COVID-19, para peserta didik "dipaksa" belajar dari rumah. Terlebih lagi tidak seluruh siswa terbiasa belajar daring (online). Bahkan dari pihak guru masih terdapat beberapa yang belum terlatih dalam penggunaan media sosial atau gadget (Purwanto \& dkk, 2020).

Program home visit di MI Salafiyah Kranggan diterapkan sejak bulan September, yang dilaksanakan dua minggu sekali dengan tujuan mengevaluasi pembelajaran daring yang sudah terlaksana. Pelaksanaan program home visit bertujuan untuk penguatan materi yang dirasa masih kurang dan belum dipahami sepenuhnya oleh siswa. Home visit diharapkan bisa meningkatkan hasil belajar siswa meskipun di tengah pandemi saat ini.

Dengan mengunjungi siswa ke rumah dan tetap menjaga jarak yang dilakukan secara bersama-sama, berpedoman pada jarak tempat tinggal siswa atau fokus dari rumah ke rumah selama tetap mengutamakan protokol kesehatan. Guru pun dapat memberi penugasan atau materi kepada masing-masing siswa melalui kegiatan berkunjung langsung dari rumah ke rumah dan dari itu dapat memunculkan literasi pertemuan serta silaturahmi berjenjang dari kurun waktu yang terstruktur.

Pembelajaran daring banyak dikeluhkan oleh berbagai pihak, karena dirasa kurang efektif (R. P. Sari \& Dkk, 2021). Kegiatan home visit sebagai strategi atau metode pembelajaran di era pandemi Covid-19 memiliki sisi baik dan sisi buruk. Pengaruh positifnya guru dapat mengevaluasi perkembangan atau kemampuan belajar dan siswa 
dapat memahami kembali materi yang kurang dipahami, sehingga tetap terjadi feed back antara guru dengan siswa.

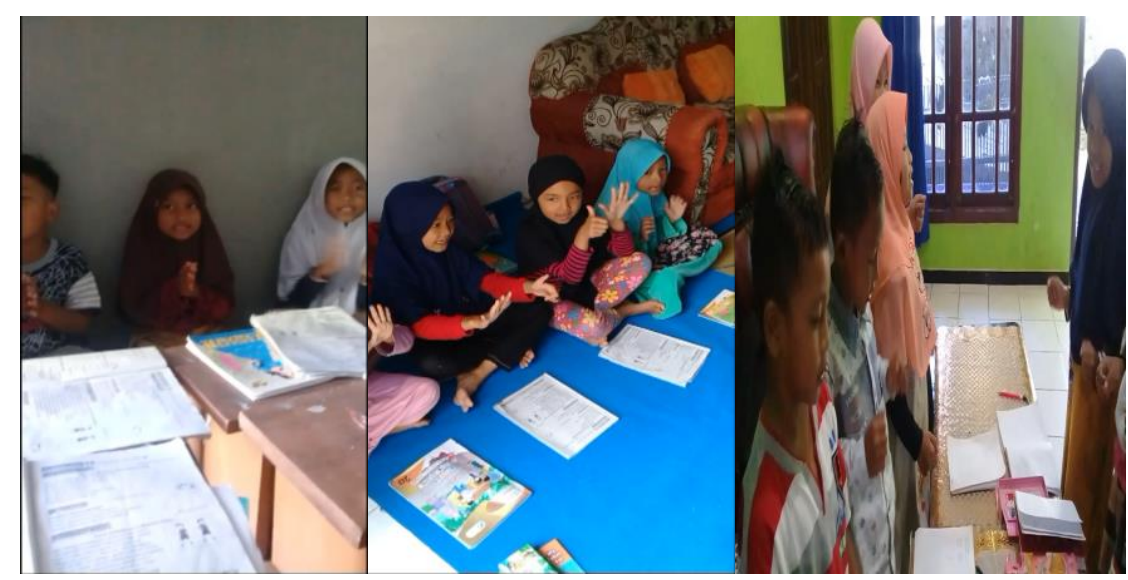

Gambar 2. Kegiatan Home Visit untuk Mengevaluasi Perkembangan dan Kemampuan Belajar Siswa MI Salafiyah Kranggan

Kegiatan home visit di MI Salafiyah Kranggan khususnya pada kelas 2 B dilaksanakan setiap hari Selasa, Kamis dan Sabtu. Pelaksanaan home visit dilaksanakan secara bersalang-seling agar siswa tidak merasa bosan. Dilain hari, guru menjelaskan materi kepada siswa dalam bentuk audio atau video melalui grup WhatsApp sekaligus memberikan tugas.

Pembelajaran dari rumah juga dinilai mengakibatkan sejumlah pengeluaran yang besar yaitu untuk membeli pulsa dan kouta internet (Cahyati \& Kusumah, 2020). Adapun pengaruh negatif dari home visit yaitu tidak efektif jika dibandingkan dengan pembelajaran tatap muka dikarenakan sarana dan prasarana yang kurang memadai di rumah. Maka dari itu guru diharuskan untuk merancang pembelajaran yang kreatif untuk meningkatkan kemampuan siswa dan minat belajar menjadi lebih besar dengan metode yang beragam. 


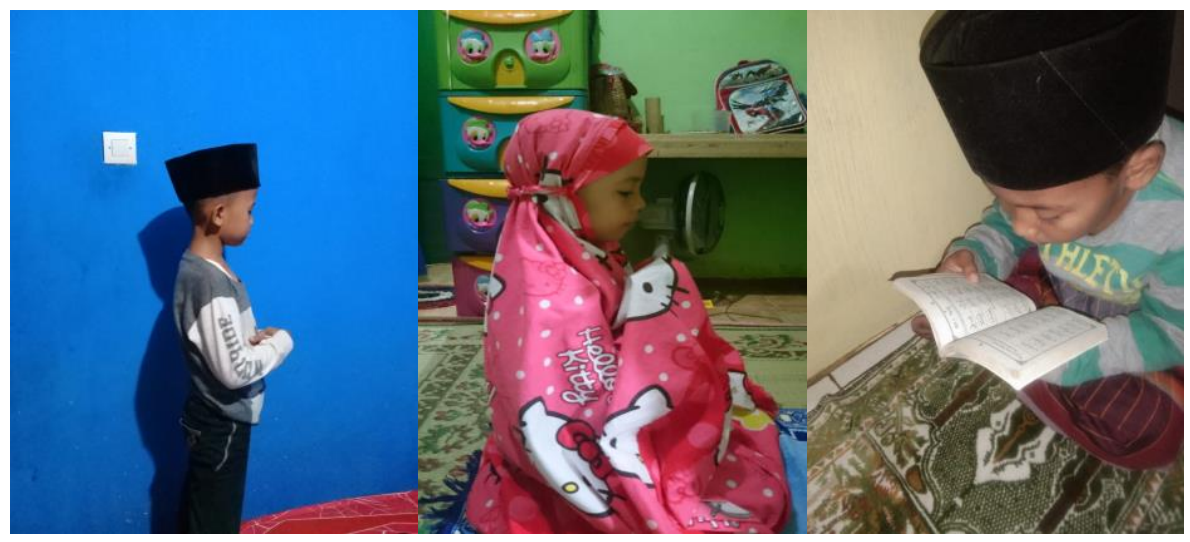

Gambar 3. Siswa Kelas 2 B MI Salafiyah Kranggan Melaksanakan Shalat, Berdoa untuk Kedua Orang Tua dan Mengaji

Saat pandemi ini Wali Kelas 2 B MI Salafiyah Kranggan menerapkan pendidikan karakter seperti menanamkan jiwa spiritual (shalat, berdoa untuk orang tua dan guru, mengaji), tingkah laku (menghormati kedua orang tua dan membantu kegiatan orang tua di rumah). Guru meminta orang tua untuk mengambil foto peserta didik saat melakukan kegiatan tersebut. Orang tua pun menginginkan diperbanyak kegiatan home visit dikarenakan tidak kunjung sekolah tatap muka, pihak sekolah juga memperbolehkan akan tetapi tetap harus berhati-hati agar tidak terkena Covid-19. Kepala Sekolah MI Salafiyah Kranggan mengatakan dalam pembelajaran tidak ada penekanan pencapaian materi, jangan memberikan tugas yang terlalu berat agar anak tidak stres. Maka dari itu, silakan pembelajaran dilakukan dengan menyenangkan.

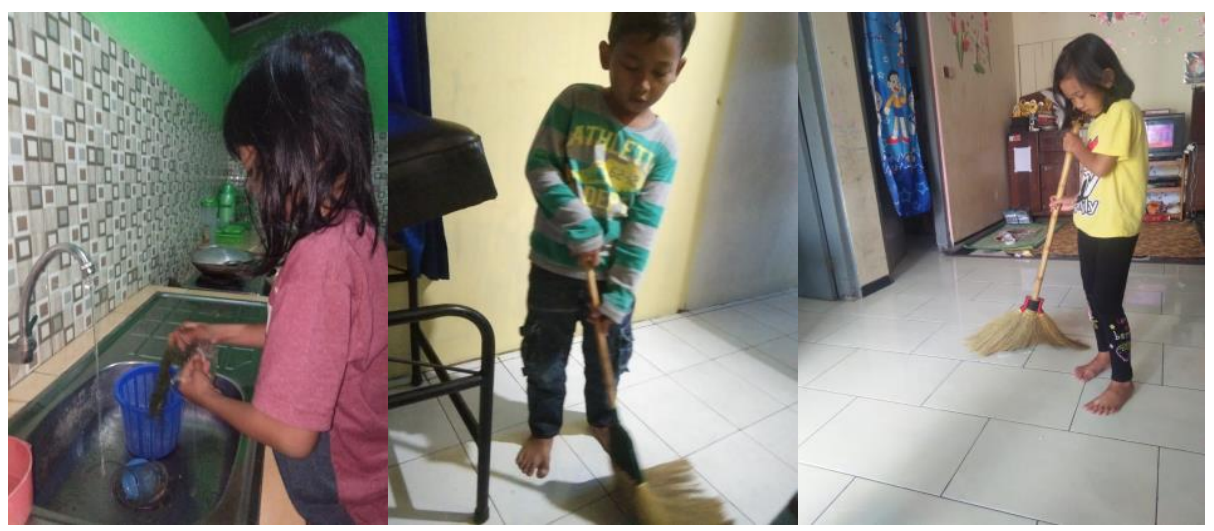

Gambar 4. Siswa Kelas 2 B Membantu Kedua Orang Tua Menyapu dan Mencuci Piring di Rumah

Setelah pembelajaran daring, peserta didik menjadi lebih dekat dengan keluarga, pendidikan berlangsung secara informal bersama keluarga, menjadi cara efektif sebagai 
penanaman moral anak, seperti memperkuat moral keagamaan anak, selain itu anak dapat pandai menggali informasi dan lebih rajin membaca buku, maupun menyimak berbagai macam materi dalam bentuk video. Dengan hal itu akan mendorong hasil belajar selama di rumah.

Sebagai pernyataan bahwa home visit dilaksanakan dalam upaya menciptakan kerjasama dan dukungan dari orang tua peserta didik untuk mengamati gaya belajar, perkembangan dan berbagai kesulitan belajar peserta didik. Selain itu home visit dilaksanakan untuk mencegah atau menghindari kerumunan siswa di sekolah sehingga tidak menimbulkan klaster baru dalam penularan COVID-19.

\section{Simpulan}

Berdasarkan analisis di atas, kebijakan pembelajaran daring dapat menunjang hasil belajar, yaitu melalui kegiatan home visit. Hal ini terbukti dari hasil penelitian yang dihimpun di lapangan dari 21 siswa kelas 2 B MI Salafiyah Kranggan menyatakan hasilnya baik. Orang tua mengalami beberapa kendala seperti kesulitan memahami dan memberikan pemahaman materi. Guru pun sepertinya mendadak untuk memaksimalkan proses pembelajaran daring. Dengan begitu program home visit di MI Salafiyah Kranggan diterapkan sejak bulan September, yang dilaksanakan dua minggu sekali dengan tujuan mengevaluasi pembelajaran daring yang sudah terlaksana. Home visit dinilai tidak efektif jika dibandingkan dengan pembelajaran tatap muka akan tetapi, pengaruh positifnya guru dapat mengevaluasi perkembangan atau kemampuan belajar dan peserta didik dapat memahami kembali materi yang kurang dipahami, sehingga tetap terjadi feed back antara guru dengan siswa. Pelaksanaan program home visit bertujuan untuk penguatan materi yang dirasa masih kurang dan belum dipahami sepenuhnya oleh siswa. Home visit diharapkan bisa meningkatkan hasil belajar siswa meskipun di tengah pandemi saat ini. Saran untuk tenaga pendidik agar memperhatikan kembali strategi yang digunakan saat home visit, sehingga pembelajaran di tengah pandemi COVID-19 ini bisa terlaksana dan terwujud dengan maksimal bersesuaian berdasarkan tujuan pendidikan.

\section{Daftar Rujukan}

Aji, W., \& Dewi, F. (2020). Dampak Covid-19 Terhadap Implementasi Pembelajaran Daring di Sekolah Dasar. Jurnal Ilmu Pendidikan, 2(1), 58.

Amalia, H. (2016). Implementasi Home Visit dalam Upaya Meningkatkan Pembelajaran PAI di SDIT al-Azhar Kediri. Didaktika Religia, 4(1), 80.

Cahyati, N., \& Kusumah, R. (2020). Peran Orang Tua Dalam Menerapkan Pembelajaran Di Rumah Saat Pandemi Covid 19. Jurnal Golden Age, 04(1), 156. 
Dwi, B., \& dkk. (2020). Analisis Keefektifan Pembelajaran Online di Masa Pandemi Covid-19. Jurnal Pendidikan Guru Sekolah Dasar, 2(1), 3.

Dwita, K. D., \& dkk. (2018). Pengaruh Home Visit dan Motivasi Belajar Terhadap Hasil Belajar Siswa di SDIT Harapan Bunda Purwokerto. Jurnal Ekonomi, Bisnis, Dan Akuntansi, 20(01), 1-15.

Nirmala, B., \& Haerul, A. (2021). Home Visit: Strategi PAUD dari Rumah bagi Guru di Daerah 3T pada Masa Pandemi Covid-19. Jurnal Obsesi : Jurnal Pendidikan Anak Usia Dini, 5(2), 1053.

Purwanto, A., \& dkk. (2020). Studi Eksploratif Dampak Pandemi COVID-19 Terhadap Proses Pembelajaran Online di Sekolah Dasar. Journal of Education, Psychology and Counseling, 2(1), 3.

Risalah, A., \& dkk. (2020). Dampak Pandemi Covid-19 Terhadap Kegiatan Belajar Mengajar di MI/SD (Studi KBM Berbasis Daring Bagi Guru dan Siswa). Journal of Islamic Education at Elementary School, 1(1), 11-12.

Sabiq, A. F. (2020). Persepsi Orang Tua Siswa tentang Kegiatan Belajar di Rumah sebagai Dampak Penyebaran Covid 19. Jurnal Ilmu Pendidikan PKn Dan Sosial Budaya, 4(1), 6.

Sari, N. P., \& Juniarti, Y. (2019). Evaluasi Peserta Didik Menggunakan Kunjungan Rumah/Home Visit, 109.

Sari, R. P., \& Dkk. (2021). Dampak Pembelajaran Daring Bagi Siswa Sekolah Dasar Selama Covid-19. Jurnal Ilmiah Kependidikan, 2(1), 11.

Setiawan, A. (2021). Pendidikan Karakter pada Peserta Didik di Masa Pandemi Covid19 Berbasis Keluarga. Jurnal Ilmiah Mandala Education, 7(1), 324. Retrieved from http://ejournal.mandalanursa.org/index.php/JIME/index

Suhendro, E. (2020). Strategi Pembelajaran Pendidikan Anak Usia Dini di Masa Pandemi Covid-19. Jurnal Golden Age, 5(3), 133-140. Retrieved from http://ejournal.uin-suka.ac.id/tarbiyah/index.php/goldenage/article/view/3394/1884

Tanjung Sari, T. (2020). Self-Efficacy dan Dukungan Keluarga dalam Keberhasilan Belajar dari Rumah di Masa Pandemi Covid-19. Journal Education Research and Development, 4(2), 133.

Zahra, T., Wardhani, Y., \& Krisnani, H. (2020). Optimalisasi Peran Pengawasan Orang Tua dalam Pelaksanaan Sekolah Online di Masa Pandemi Covid-19 Universitas Padjadjaran. Journal Prosiding Penelitian \& Pengabdian Kepada Masyarakat, 7(1), 49.

Ziah, R. B. H., \& Erny, R. (2013). Implementasi Program Home Visit dalam Optimalisasi Hasil Belajar di MINU Trate Putri Gresik, 1-12. 